\title{
How can aerosols affect the Asian summer monsoon? Assessment during three consecutive pre-monsoon seasons from CALIPSO satellite data
}

\author{
J. Kuhlmann ${ }^{1,2,{ }^{*}}$ and J. Quaas ${ }^{1}$ \\ ${ }^{1}$ Max Planck Institute for Meteorology, Hamburg, Germany \\ ${ }^{2}$ TU Dortmund, Dortmund, Germany \\ *now at: GFZ German Research Centre for Geosciences, Potsdam, Germany \\ Received: 21 January 2010 - Published in Atmos. Chem. Phys. Discuss.: 18 February 2010 \\ Revised: 10 May 2010 - Accepted: 17 May 2010 - Published: 21 May 2010
}

\begin{abstract}
The impact of aerosols above and around the Tibetan Plateau on the Asian Summer Monsoon during premonsoon seasons March-April-May 2007, 2008, and 2009 is investigated by means of remote sensing and radiative transfer modelling. Four source regions are found to be responsible for the high aerosol loading around the Tibetan Plateau: the Taklamakan Desert, the Ganges Plains, the Indus Plains, and the Arabian Sea. CALIPSO lidar satellite data, providing vertically resolved images of aerosols, shows aerosol concentrations to be highest in the lower $5 \mathrm{~km}$ of the atmosphere with only little amounts reaching the Tibetan Plateau altitude. Using a radiative transfer model we find that aerosol plumes reduce shortwave radiation throughout the Monsoon region in the seasonal average by between 20 and $30 \mathrm{~W} / \mathrm{m}^{2}$. Peak shortwave heating in the lower troposphere reaches $0.2 \mathrm{~K} /$ day. In higher layers this shortwave heating is partly balanced by longwave cooling. Although high-albedo surfaces, such as deserts or the Tibetan Plateau, increase the shortwave heating by around $10 \%$, the overall effect is strongest close to the aerosol sources. A strong elevated heating which could influence large-scale monsoonal circulations as suggested by previous studies is not found.
\end{abstract}

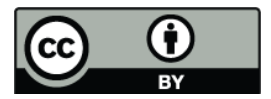

Correspondence to: J. Kuhlmann (julian@gfz-potsdam.de)

\section{Introduction}

Over sixty percent of the world's population depends on water supply from the Asian Summer Monsoon. The coincidence of natural and anthropogenic aerosol sources in Asia leads to high aerosol concentrations throughout the southern part of the continent (Chung et al., 2005). Aerosols in the monsoon region have been the subject of extensive research (e.g. Lau et al., 2008; Ramanathan et al., 2001; Lelieveld et al., 2001). In this study, we investigate aerosol impacts on the Asian monsoon system by means of remote sensing and radiative transfer modelling.

Aerosols are a major source of uncertainty in both the attribution of past climate change and in future climate projections (Forster et al., 2007). This is a result of their short lifetimes and the numerous ways they interact with other elements of the climate system (Kaufman et al., 2002). Their direct impact on solar and terrestrial radiation in an atmospheric column is commonly estimated with radiative transfer models (RTMs) (e.g. Tafuro et al., 2007; Xia and Zong, 2009).

Anthropogenic aerosols around the Tibetan Plateau (TP) have their sources both in the Indian and Chinese megacities but also in the rural areas. The population growth accompanied by industrialization led, for instance, to a 6 -fold increase in South Asian emissions of fossil fuel $\mathrm{SO}_{2}$ and black carbon since 1930 (Ramanathan et al., 2005). Organic carbon released by biomass burning further aggravates the air pollution as it accounts for about two thirds of the carbonaceous aerosol in South Asia (Gustafsson et al., 2009).

Published by Copernicus Publications on behalf of the European Geosciences Union. 
Natural aerosols in the region originate mainly from local and remote deserts. The structure, distribution, and transport of this dust has been the subject of wide research (Huang et al., 2007, 2008; D. Liu et al., 2008; Z. Liu et al., 2008; Xia et al., 2008). The concentration of natural aerosol in the region varies strongly from year to year (Gautam et al., 2009b). Mineral dust originating from the Taklamakan Desert (TD) north of the TP is transported over very long distances. For instance, scientists have found this dust in the ice in Greenland and in the French Alps (Hara et al., 2008). Yet it is unclear whether dust above the TP itself originates from the surrounding regions or whether it is generated on the spot.

In the densely populated region of Southern Asia, the monsoon crucially affects the inhabitants' physical and economical well-being. There is a strong positive correlation between precipitation amount and food production (Ramanathan et al., 2005). Furthermore, the uneven distribution of monsoon rain, causing either floods or droughts, regularly results in loss of human lives and damage of crops and property (Lau et al., 2008).

The impact of aerosols on the Asian Summer Monsoon is disputed. It is still unclear whether aerosols could strengthen or weaken the monsoon. While sunlight-absorbing aerosols, especially in the higher troposphere above and around the TP, might lead to an increased Hadley circulation during pre-monsoon season (March-April-May) and therefore to a subsequently strengthened monsoon (Lau et al., 2006; Lau and Kim, 2006; Randles and Ramaswamy, 2008), there are opposing theories suggesting a weakening of the land-seacontrast by solar dimming (Ramanathan et al., 2005) or by increased cloudiness resulting from the strengthened Hadley circulation (Collier and Zhang, 2009). The impact might also vary from month to month and from region to region (Menon et al., 2002; Bollasina et al., 2008; Meehl et al., 2008) or the dust above the TP might be the result rather than the cause of a strengthened monsoon (Gautam et al., 2009a). In a recent model study, Wang et al. (2009) stressed the importance of absorbing aerosols increasing moist static energy during premonsoon season, which resulted in a simulated northward shift of monsoon precipitation.

This work is inspired by the papers written by K.-M. Lau and co-authors (Lau et al., 2006; Lau and Kim, 2006) and the Elevated Heat Pump (EHP) hypothesis they propose therein. Their idea was to run the NASA finite volume atmospheric general circulation model (fvGCM) (Lin et al., 2004) first without any aerosol forcing as a control run, then with realistic aerosol distributions as an anomaly experiment. The difference between the two runs revealed aerosol impacts on the monsoonal system in the form of strong heating over the slopes of the TP due to absorption of sunlight by dust advected from neighboring deserts and black carbon from local pollution. In their simulation, the heating is particularly strong above high-albedo surfaces such as snow-covered mountain slopes, even though Aerosol Optical Depth (AOD) is not especially high at these altitudes. The meridional tem- perature gradient, seen as a main driver for the Asian Summer Monsoon, is therefore increased. The heated air above the elevated surfaces rises and draws in warm, moist air from the Indian Ocean. This is the effect Lau et al. (2006) called "Elevated Heat Pump" (EHP); it leads to an earlier and stronger monsoon. Both wind speed and precipitation were simulated to strengthen.

The EHP hypothesis has been widely discussed in the literature; numerous scientists have adopted the idea (e.g. Huang et al., 2007; D. Liu et al., 2008; Z. Liu et al., 2008; Meehl et al., 2008; Ramanathan and Carmichael, 2008; Randles and Ramaswamy, 2008; Collier and Zhang, 2009) and the original authors have continued to explore it (Lau and Kim, 2006; Lau et al., 2008; Bollasina et al., 2008; Gautam et al., 2009a). Nevertheless, there are three major limitations to the study. First, the Lau et al. (2006) study was lacking interaction of atmospheric processes with the ocean. Sea Surface Temperatures (SSTs) were prescribed to observed values, a common method, yet when Bollasina et al. (2008) compared different studies of aerosol impact on the Asian Summer Monsoon, they noticed that those using coupled oceanatmosphere models yielded opposing results to those using models with prescribed SSTs. Second, aerosol indirect effects have been omitted. Third, and maybe most important, the information about vertical distribution of aerosol concentrations was sparse. This last point is crucial as the theory of an "Elevated Heat Pump" is based on the assumption that the direct aerosol effect is reinforced in high altitudes and above bright surfaces. These bright surfaces, however, exist mainly in high altitudes, e.g. on snow-covered Himalayan mountains. For aerosols to interact with these surfaces, they have to ascend at least up to $5 \mathrm{~km}$ a.m.s.l. (above mean sea level). The Cloud-Aerosol Lidar and Infrared Pathfinder Satellite Observations (CALIPSO) satellite gives us the possibility to learn whether or not this condition is fulfilled.

We will begin with presenting the data and methods employed in this study (Sect. 2). Thereafter, we will use CALIPSO data from the pre-monsoon seasons March-AprilMay (MAM) 2007, 2008, and 2009 to monitor aerosol distributions above and around the TP (Sect. 3) as well as their possible transport pathways (Sect. 4). Finally, we will estimate aerosol radiative impacts in the region with an RTM (Sect. 5). The results might indicate which of the various proposed mechanisms for aerosol-monsoon interactions fit to the observations and which do not.

The geographical region relevant for this study is the TP as well as surrounding regions from which aerosols might be advected. The choice of the region of interest (ROI) is motivated as follows: CALIPSO roughly covers the regions surrounding the TP every day. Taking into account wind speeds in the order of $40 \mathrm{~km} / \mathrm{h}$, an aerosol layer might advance around $1000 \mathrm{~km}$ between one CALIPSO measurement and the next. In order to capture every aerosol plume that might reach the TP within the following day, we define a ROI that stretches from $20^{\circ} \mathrm{N}$ to $50^{\circ} \mathrm{N}$ and from $60^{\circ} \mathrm{E}$ to 
$120^{\circ}$ E, see Fig. 1. Also marked in the figure are sub-regions of special interest: The TP as target region and the Arabian Sea (AS), the Ganges Plains (GP), the Indus Plains (IP), and the TD as likely source regions.

\section{Data and methods}

\subsection{CALIPSO satellite data}

The Cloud-Aerosol Lidar and Infrared Pathfinder Satellite Observations (CALIPSO) is a satellite developed by NASA and CNES for the monitoring of cloud and aerosol properties (Winker et al., 2003). It carries the Cloud-Aerosol Lidar with Orthogonal Polarization (CALIOP), an active polarizationsensitive lidar instrument which produces vertically resolved images of cloud and aerosol layers as well as their respective optical properties (Winker et al., 2006). Unlike earlier remote sensing instruments, CALIPSO can reliably detect aerosol over bright surfaces, e.g. deserts, and beneath thin clouds.

CALIPSO was launched on 28 April 2006. It orbits the earth on a sun-synchronous orbit at $705 \mathrm{~km}$ altitude. The inclination, i.e. the angle between the earth's equatorial plane and the satellite's orbital plane, is $98.2^{\circ}$. Each day, the satellite orbits the earth 15 times. Measurements are taken both in the daytime and in the nighttime parts of the track, with data for three years available.

The data is available online from NASA (http://eosweb. larc.nasa.gov/PRODOCS/calipso/table_calipso.html). During this study, we use mainly Level 2-data, which provides top and base altitudes of aerosol or cloud layers identified by NASA retrieval algorithms. In the present study we use aerosol layer top altitude, base altitude, optical depth at $532 \mathrm{~nm}$, aerosol type, and surface elevation as functions of latitude and longitude. The dataset for MAM 2007, 2008, and 2009 consists of 1390 CALIPSO tracks that cover the ROI. The results are qualitatively insensitive to a particular choice of a pre-monsoon season (e.g. April-May instead of March-April-May).

Level 2-data comes with a classification of the detected aerosol layers. According to its radiative properties, each aerosol layer is assigned to one of six aerosol classes (clean marine, dust, polluted continental, clean continental, polluted dust, and smoke). This classification is documented in Omar et al. (2004) and in Liu et al. (2005). Each aerosol class is a mixture of aerosol particles of a different composition characteristic for a specific source region or an air mass. Mixtures of two classes are therefore not assigned to one aerosol layer.

There are several uncertainties associated with the CALIPSO data. For instance, the measurements are carried out along narrow tracks that are separated by large areas without measurements; the lidar instrument cannot measure aerosols beneath thick clouds; and due to the lidar wave-

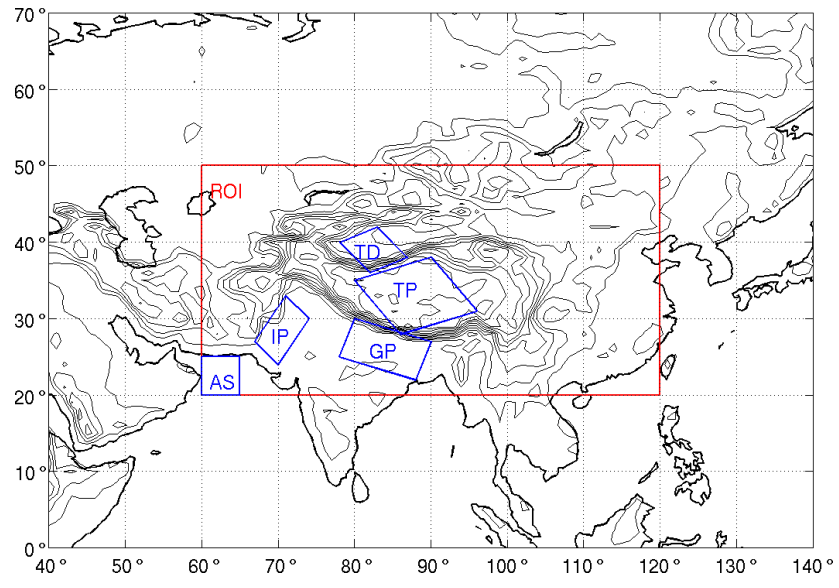

Fig. 1. Map of the Region of Interest (ROI) in red and the different subregions in blue: Arabian Sea (AS), Ganges Plains (GP), Indus Plains (IP), Taklamakan Desert (TD), and Tibetan Plateau (TP). Thick black lines indicate the coast, thin black lines represent levels of equal altitude (each $500 \mathrm{~m}$ ).

length within the solar spectrum, the instrument is more sensitive during nighttime than during daytime. However, it is the only satellite providing global three-dimensional aerosol measurements in a region where in-situ observations are sparse. Furthermore, the issue of cloud attenuation turns out to be of minor importance in the regions considered here: even for atmospheric layers close to the surface, CALIPSO provides aerosol data in around 80 to $90 \%$ of the cases. However, in cloudy skies potential direct radiative effects of aerosols, especially in the shortwave, would presumably be small, so neglecting this should only imply a small error.

\subsection{NCEP/NCAR reanalysis wind data}

Data for wind patterns in the region is obtained from the NCEP/NCAR Reanalysis Project (http://www.cdc.noaa. gov/cdc/reanalysis/reanalysis.shtml). The NCEP/NCAR Reanalysis Project creates wind fields by assimilating rawinsonde measurements, cloud-tracked winds from geostationary satellites, aircraft observations, and oceanic reports (Kistler et al., 2001). Wind data in $u$-, $v$ - and $\omega$-direction are available on a $2.5^{\circ} \times 2.5^{\circ}$ grid for each day.

\subsection{The radiative transfer model}

The radiative effects of aerosols depend on various factors, such as AOD, complex aerosol refractive indices, size distributions, properties of the surrounding air, and surface properties. The application of an RTM can yield quantitatively realistic estimations of these effects. The model used in this study was developed by Stefan Kinne at the Max Planck Institute for Meteorology, Hamburg. It is described in Tafuro et al. (2007). In the model, the direct aerosol radiative effect is simulated based on Mie scattering. 
The RTM simulates the radiative transfer using an independent column approximation with 46 layers with varying aerosol concentration and optical properties. In aerosolfree layers, the model simulates a standard tropical atmosphere, including greenhouse gases $\left(\mathrm{CO}_{2}, \mathrm{O}_{3}, \mathrm{~N}_{2} \mathrm{O}, \mathrm{CO}\right.$, $\mathrm{CH}_{4}$, and water vapor). $\mathrm{CO}_{2}$ concentrations are fixed at a present-day value of $380 \mathrm{ppm}$ and $\mathrm{CH}_{4}$ at $1700 \mathrm{ppb}$. The other greenhouse gases are set to altitude-dependent distributions typical for the tropics. The scattering by atmospheric molecules is calculated following Rayleigh scattering theory which is appropriate for cases of scattering particles significantly smaller than the typical wavelengths of the radiation, such as gas molecules. Profiles of pressure, temperature and water vapour mixing ratio are set to tropical standard values.

The RTM models the solar radiation with eight spectral bands of wavelengths $\lambda$ from 0.35 to $3.00 \mu \mathrm{m}$ (cf. Table 1), i.e. in the visible and near infrared spectral regions. The thermal infrared radiation emitted by the earth is represented by twelve spectral bands with $\lambda$ from 4.25 to $80.00 \mu \mathrm{m}$. This approach allows for wavelength-dependent optical properties of aerosols, atmospheric molecules, and surface albedo. Depending on the latitude, the model calculates radiative impacts for different solar angles throughout the diurnal cycle to obtain a daily average. The model approximates the scattered radiation's angular distribution to the theoretical result for Mie scattering with the major part scattered towards the surface and the minor part scattered back to the sky. Additionally, it superimposes a delta peak in the exact forward direction.

The surface albedo for the solar radiation is adjustable in the RTM as well. One may either fix the albedo to a wavelength-independent value or define a spectral function for the albedo. The RTM allows to chose four typical surface types: land, ocean, desert and ice. The albedo's spectral dependence for the land-presetting is representative for vegetated regions (Table 1). In the ocean-presetting, the albedo is a function of both wavelength and solar zenith angle.

Tafuro et al. (2007) learned in their simulations with the very same model that albedo effects were particularly important. As they did in their study, we also use Moderate Resolution Imaging Spectroradiometer (MODIS) satellite albedo data from the MOD43B3 product on a $1 / 60^{\circ} \times 1 / 60^{\circ}$ grid. This product is available for several wavelengths. Since absorption and scattering of solar radiation is thought to be the predominant direct aerosol effect, we chose the albedo product for the spectral region of 0.3 to $5.0 \mu \mathrm{m}$. Note that we vary only the shortwave (SW) albedo; the longwave (LW) albedo remains fixed to 0.04 .

Furthermore, the model can simulate cloud layers in addition to aerosol layers. In this study, however, we only consider cloud-free skies, an assumption which maximises aerosol direct radiative effects. Including clouds into our simulations would be more realistic, though it would also introduce new uncertainties due to imperfect estimation of cloud optical properties. Since we are concerned with
Table 1. Spectral dependence of the surface albedo in the RTM for simulations with the land-presetting.

\begin{tabular}{|c|c|c|}
\hline & Wavelength $[\mu \mathrm{m}]$ & Albedo \\
\hline \multirow{8}{*}{ SW } & 0.35 & 0.03 \\
\hline & 0.45 & 0.03 \\
\hline & 0.55 & 0.06 \\
\hline & 0.65 & 0.04 \\
\hline & 1.00 & 0.40 \\
\hline & 1.60 & 0.25 \\
\hline & 2.20 & 0.15 \\
\hline & 3.00 & 0.15 \\
\hline LW & $4.25-80.00$ & 0.04 \\
\hline
\end{tabular}

aerosol-induced anomalies only, the simulation of aerosols in clear-sky conditions seems justified.

\section{Satellite measurements of vertical aerosol distributions}

Compared to previous remote sensing instruments capturing aerosol characteristics, CALIPSO has mainly two new features: it is able to detect the vertical dimension of aerosol layers and it distinguishes between different aerosol types in more detail.

In Fig. 2, the bottom $10 \mathrm{~km}$ of the atmosphere are cut in layers of $100 \mathrm{~m}$ height. Then, for each measurement along the CALIPSO track, we determine whether or not aerosols with an optical depth above the detection threshold were identified in a layer. The probability distributions shown are normalized by the number of measurements at the altitude in question since the number of total measurements is lower at low altitudes: the lidar does not give any information for points beneath the surface or below altitudes at which the signal is fully attenuated. As a measure of variability, we divided each subregion into four equal-sized parts and used error bars to indicate the value of the lowest and highest quarter. These error bars cannot account for various other error sources, such as instrument errors, cloud and molecular scattering, or noise from solar illumination, but they provide an idea of the geographical variability within the subregion.

Figure 2a shows the vertical distribution of the different aerosol types in the entire ROI (see Sect. 1 for the definition of the ROI and the sub-regions). Dust is the most important aerosol, with around $20 \%$ of all measurements between 1 and $3 \mathrm{~km}$ above sea level affected. Polluted dust is about half as prominent in the region. Although smoke is somewhat present in Fig. 2a, its regional distribution shows that it is less likely to be advected near the TP or central India, therefore being less important to the monsoonal system: smoke is abundant mainly in South-East Asia and China. 

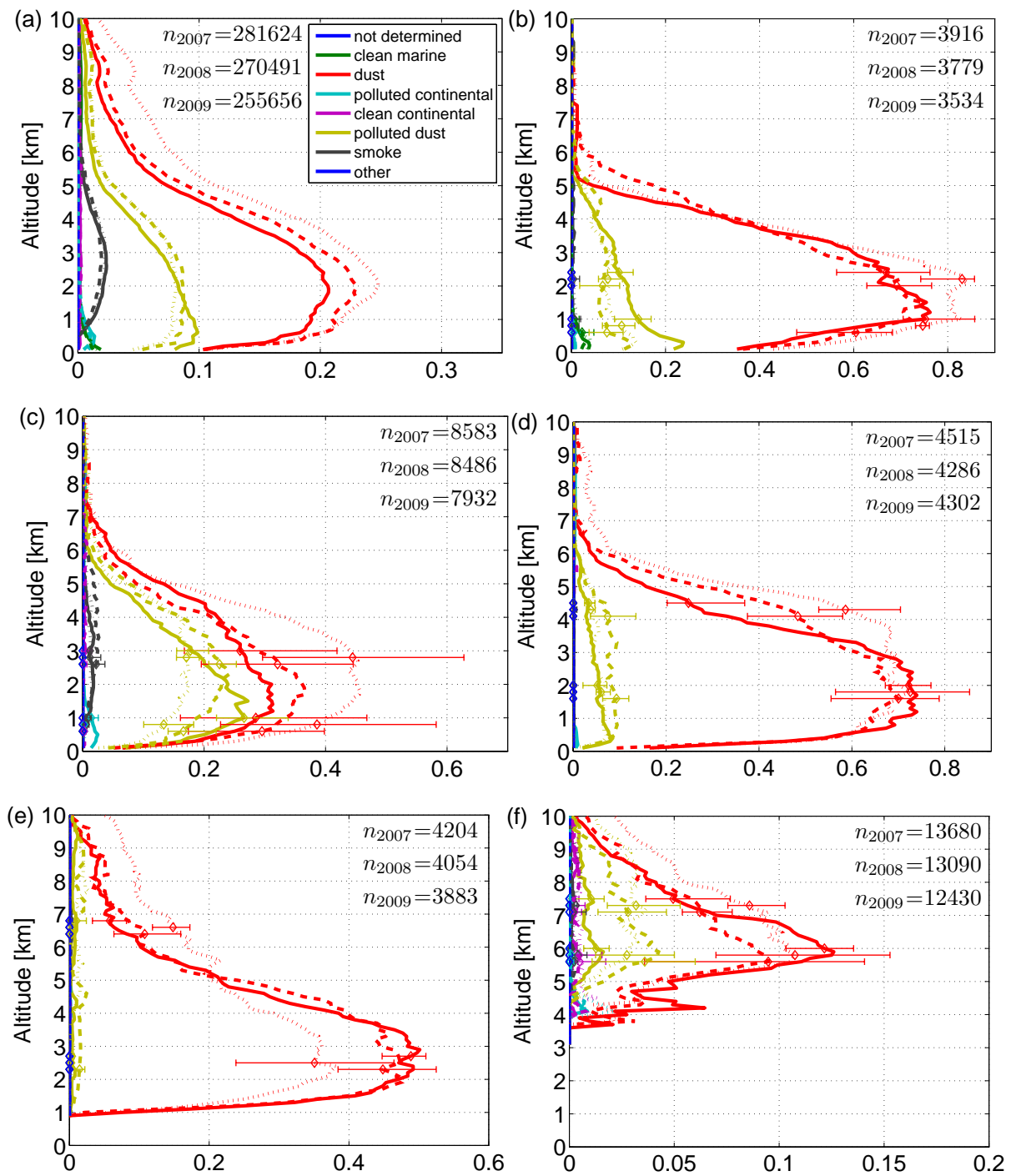

Fig. 2. Vertical distribution of the frequency of occurrence of the different aerosol types in (a) the entire region of interest, (b) the Arabian Sea, (c) the Ganges Plains, (d) the Indus Plains, (e) the Taklamakan Desert, and (f) the Tibetan Plateau. Note the different scalings of the respective x-axis. Data displayed separately for MAM 2007 (solid lines), 2008 (dotted lines), and 2009 (dashed lines). The numbers $n_{x}$ indicate the total number of sample profiles that was considered for each averaged profile. The error bars indicate the geographical variability within the subregions.

Considering the different sub-regions (Fig. 2b through 2f), important differences are visible. Figure $2 \mathrm{~b}$ shows that above the AS, there are high dust loadings with up to $80 \%$ of the measurements detecting either dust or polluted dust. Polluted dust above the AS has previously been observed by Pease et al. (1998) and Tindale and Pease (1999). The dust plumes above the AS, however, are mostly confined to lower atmospheric layers. CALIPSO hardly detects any dust above $5 \mathrm{~km}$, the crucial altitude determining whether the aerosols can reach the TP and produce additional upper level heating which would enhance the monsoonal circulation. The dust advected from the AS towards the TP is likely to cross the IP (Fig. 2c). The concentrations in the IP are equally high, which can be due to advected Arabian dust or local sources, for instance the Thar Desert. In this region, the maximum altitude of dust elevates to around $7 \mathrm{~km}$. A very different pattern in the vertical aerosol distribution can be seen above the GP (Fig. 2c). We may note two major differences: first, the frequency of occurrence of dust reaches only values of 0.3 to 0.45 , depending on the year, considerably less than above the AS and the IP. We can attribute this to the fewer local dust sources, as there are no major deserts in the GP. Second, CALIPSO detects high amounts of polluted dust, the frequency of occurence reaches around 0.2. Population density in this region is among the highest in the world, hence the dust is coated by carbon or sulfate aerosols which reinforces 
its radiative properties. As above the IP, the dust above the GP rises to about $7 \mathrm{~km}$.

The TD region (Fig. 2e) is sparsely populated, and advection of polluted aerosols is effectively blocked by the mountains of the TP. Therefore, only pure dust originating from local sources exists here. The dust in this region rises to higher altitudes than anywhere else - sometimes up to around $10 \mathrm{~km}$. This is likely due to local topography since the desert is surrounded by mountain ranges. Hence, dust transport from the TD to the TP seems plausible. Xia et al. (2008), who investigated aerosol transport on this pathway, observed it to occur much more often during summer than during spring. They explained dust occurrences above the TP in spring with local dust emissions rather than with advection from the TD.

Aerosols above the TP itself are mostly dust, occasionally mixed with polluted dust (Fig. 2f). Polluted dust is only measured south, not north of the TP, thus beyond the highest mountains. From the occurrence of polluted dust above the TP we conclude that aerosol advection from both sides of the $\mathrm{TP}$ is occurring, despite its diminutive quantities.

The interannual comparison shows little variation in most cases. Only the occurrence of dust in MAM 2008 was exceptionally weak in the TD, while it was exceptionally strong in the GP and in upper layers above the IP. Averaged over the entire ROI, 2008 was the strongest dust period.

\section{Combination of wind and aeorsol data}

The EHP hypothesis of aerosol-monsoon interaction is based on aerosol transport towards the slopes of the TP. In order to determine the most prominent source regions for this kind of transport, we combine CALIPSO aerosol data and NCEP/NCAR reanalysis wind data. There are two necessary conditions for aerosol transport from a given geographical location to the TP: first, aerosols must be present in atmospheric layers higher than the elevation of the TP. Second, the local wind must be directed towards the TP.

We inspect the first condition with the CALIPSO aerosol data: for each day during the pre-monsoon-season and for each geographical location we determine if aerosol layers exist above the maximum TP elevation in the respective CALIPSO track. Thereby, we account for the varying elevation of the TP. In the case of multiple CALIPSO measurements in close vicinity with differing outcome, we declare that the region under consideration contains aerosols and the first condition is fulfilled.

Subsequently, we inspect the second condition. This is done with the NCEP/NCAR reanalysis wind data. We investigate the horizontal $(u, v)$ wind vector and determine whether this vector is directed towards the TP. Therefore, we trace the shape of the TP slopes with a polygon structure. The blue lines in Fig. 3 depict this sequence for the northern as well as for the southern slopes. If the wind vector is directed towards the TP slopes, i.e. if the extension of the wind
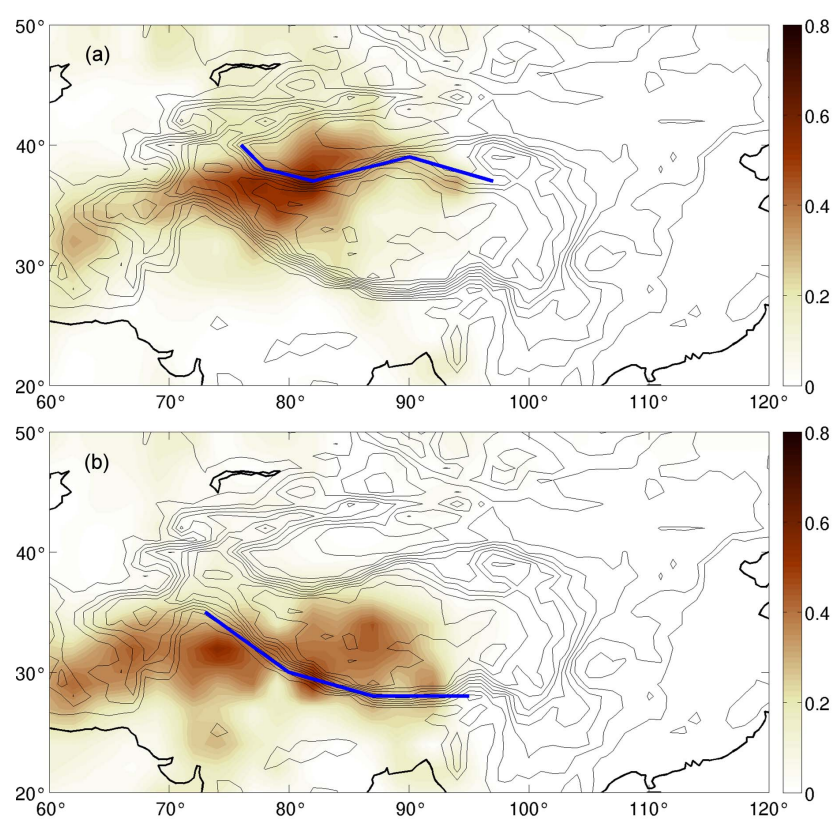

Fig. 3. Fraction of days when aerosols are blown towards the (a) northern and (b) southern slopes of the Himalaya (indicated by the blue lines) during MAM 2007, 2008, and 2009.

vector intersects with a part of the blue polygon, the second condition is fulfilled. An approximation in this context is the conversion from the vertical coordinates of the CALIPSO data, which are given in $\mathrm{km}$, to the vertical coordinates of the NCEP/NCAR reanalysis wind data, which are given in $\mathrm{hPa}$. We chose the pressure level of $500 \mathrm{hPa}$, since, in accordance to the 1976 US Standard, it roughly corresponds to the altitude in question (between $5.5 \mathrm{~km}$ and $8 \mathrm{~km}$ ).

Lastly, for each location, we divide the number of cases for which both conditions are fulfilled by the number of cases for which only the first condition is fulfilled. Thereby, we obtain a geographical distribution of the portion of elevated aerosols at each location that are advected towards the slopes of the TP.

Figure 3 shows this fraction. Quantitatively, note that in some regions with heavy aerosol production, e.g. Thar or Taklamakan, 40 to $60 \%$ of all available aerosols above the threshold are blown towards the TP. Comparing this to the profiles in Fig. 2, aerosol amounts contributing to a possible EHP can be estimated quantitatively. Aerosols from the IP are likely to be advected to the slopes of the TP Meanwhile, the GP is located slightly to the south of the slopes, which lets the westerlies transport the local pollution and dust away from the monsoon region towards East Asia. Desert dust from the Arabian Peninsula is more likely to reach the slopes of the TP if its transport pathway crosses not the Arabian Sea but Iran and Pakistan, from where around $40 \%$ of all elevated aerosols are advected towards the TP. Note that pollution from agglomerations in Eastern China and dust from Gobi 
Desert, although quantitatively important, cannot contribute to a possible EHP. The predominant westerlies blow these aerosols away from the TP. This finding using statistics from three entire spring seasons matches with the results of a case study performed by Eguchi et al. (2009), who observed dust and pollution plumes from Gobi and Taklamakan Deserts being advected across the Pacific towards North America. It suggests that aerosols from Eastern China and Gobi Desert cannot influence the Asian Summer Monsoon via the EHP mechanism.

\section{Radiative impacts of aerosols: the radiative transfer model}

\subsection{Preparation of the RTM}

In order to simulate the radiative impacts of the aerosol layers detected by CALIPSO, the RTM described in Sect. 2 needs certain modifications. We define an atmospheric column of 46 layers. The lower 40 layers - the only ones that can contain aerosols - are each $0.2 \mathrm{~km}$ thick. The top height of the 40th layer is therefore situated at $8 \mathrm{~km}$ above sea level. Aerosol occurrence above $8 \mathrm{~km}$ is extremely rare, so omitting its possibility should not bias the results. The lower boundary of the atmospheric column is fixed at $0 \mathrm{~km}$ a.m.s.l. This simplification introduces errors of $5 \%$ at most, which is negligible compared to the uncertainties in satellite retrievals of aerosols. Above $8 \mathrm{~km}$, we build in 6 layers covering the atmosphere up to $50 \mathrm{~km}$. Thereby, we account for the effects of UV absorption by the ozone layer in the stratosphere. A coarser vertical resolution is adequate for our purpose since the stratosphere is more homogeneous than the troposphere.

CALIPSO satellite data is the input source for the RTM. The CALIPSO Level 2-data contains top and base altitude of aerosol layers, the optical depth, as well as a classification of aerosol types ("clean marine", "dust", "polluted continental", "clean continental", "polluted dust", "smoke", "other") for every layer. For each of these aerosol types, Omar et al. (2004) described approximate size distributions and optical properties. We use these values to produce a standard input file for each aerosol type. This file can later be treated by the RTM. These standard input files are set up so they produce an aerosol layer of the given type with an AOD of 0.1 per $\mathrm{km}$. In the application of the model, the aerosol concentration in a given layer will be scaled by the actual AOD measured by CALIPSO.

\subsection{Application method}

Each CALIPSO laser shot produces a one-dimensional profile of the atmospheric column measured approximately at nadir. Each of the files provided by NASA contains several thousands of these profiles along a track across the globe. Figure 4 depicts an extract of one such track. Each one of the profiles can be used as input source for the RTM. The result can finally be displayed in a way that makes it easily comparable to the initial satellite data. This approach is similar to that of Huang et al. (2009) who also passed CALIPSO data as input to an RTM.

To begin the analysis of the RTM results, it is useful to chose an exemplary day of CALIPSO data and perform different simulations with this aerosol data. As case studies we chose such CALIPSO tracks that comprise several regions that are crucial for the theories in question (cf. Sect. 1), for instance the Ganges Plains (GP), the Tibetan Plateau (TP) and the Taklamakan Desert (TD). Furthermore, the days we chose are such with heavy aerosol loading above and around the TP. Four days during MAM 2007 notably meet these requirements: 30 April, 14 May, 16 May, and 30 May. All of the data considered for the case studies has been recorded during nighttime, when the instrument is more sensitive to aerosol signals (Z. Liu et al., 2008). While the particular numerical values for the different simulated physical quantities vary from case to case, the basic features are always similar. Therefore, in this Section, we show results for 14 May only.

CALIPSO images of 14 May are shown in Fig. 4. Both north and south of the TP, thick aerosol layers are present. Even though they do not reach much higher than approximately $5 \mathrm{~km}$, a certain amount of aerosol is present above the TP. Few clouds are present; this simplifies the analysis. The air above the GP contains both pure and polluted dust, while the aerosol layers above the TP consist mostly of pure dust. Apart from rare smoke occurrence, other aerosol types are not present in this scene. The separation of aerosol types by the TP - polluted dust is absent north of the mountains - is an indication of the unlikelihood of cross-TP aerosol transport.

The CALIPSO data which is shown in Fig. 4 is subsequently used as input for the RTM. The runs differ on whether aerosols are included or not and on whether the surface albedo is fixed or varies according to MODIS satellite data. Like this, it is possible to compute anomalies of the radiative budget induced by aerosols and to quantify the effect of high-albedo surfaces on the aerosol heating.

\subsection{Case study of 14 May 2007}

All plots shown are normalized by an aerosol-free atmosphere with only molecular scattering and absorption. The model run with CALIPSO aerosol distribution and MODIS albedo is normalized by a model run with the same albedo but no aerosols. Thus, the anomalies in fluxes and heating rates are solely due to aerosols. For instance, the heating rate anomaly due to aerosols is

$$
\Delta_{\mathrm{aes}}=\left[\left(\frac{\partial T}{\partial t}\right)_{\mathrm{AA}}-\left(\frac{\partial T}{\partial t}\right)_{\mathrm{NA}}\right]_{\mathrm{MODIS}},
$$

where the indices signify whether all aerosols (AA) or no aerosols (NA) were included in the simulation. The index MODIS indicates that in both simulations the albedo values retrieved by MODIS have been implemented. 


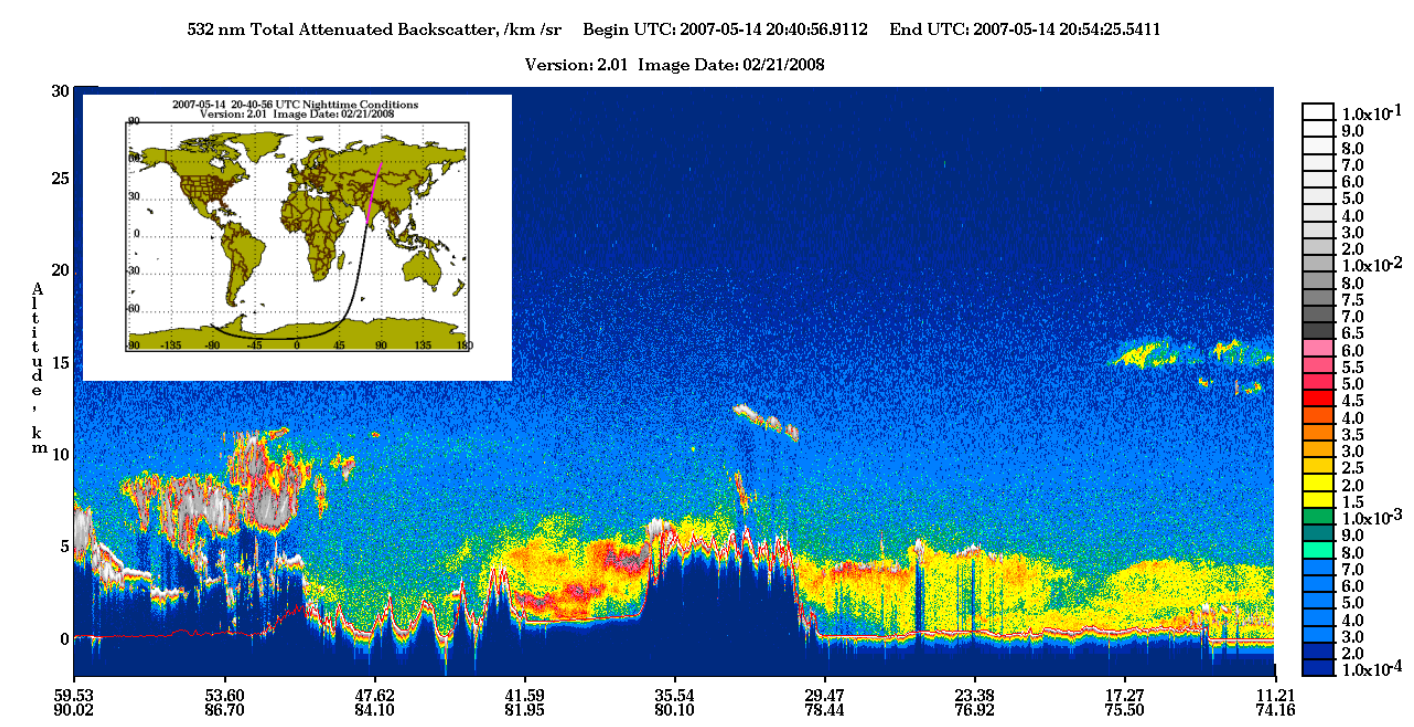

Fig. 4. CALIPSO backscatter signal for the case study of 14 May 2007. Vertically resolved total attenuated backscatter along the track. The $\mathrm{TP}$ (between approximately $30^{\circ} \mathrm{N}$ and $35^{\circ} \mathrm{N}$, geographical coordinates are shown on the $\mathrm{x}$-axis) is enclosed by aerosol layers, both from the southern and from the northern sides. Grey colour corresponds to clouds, yellow to red colours correspond to aerosol layers. Top-left corner: a map of the CALIPSO track used for the case study. The Indian subcontinent, the Himalaya and the Taklamakan Desert are covered. Image from http://www-calipso.larc.nasa.gov/.

The result for the anomalies in SW fluxes is shown in Fig. 5a. The downward flux at the top of the atmosphere (TOA) is not changed by aerosols in the atmosphere below, thus the green dots are all on the $\mathrm{x}$-axis. The downward flux at the surface is reduced by around 80 to $120 \mathrm{~W} / \mathrm{m}^{2}$ in the TD where thick homogeneous aerosol layers are present. In the GP, aerosol concentrations are more variable, and so are the SW flux anomalies at the surface, but they are of the same order of magnitude. It is now apparent that the aerosol layers above the TP that were visible in Fig. 4 have little impact on the radiative fluxes in the modeled atmosphere. Even though they are advected to high altitudes and above bright surfaces, they leave the downward SW flux at the surface virtually unaltered.

Aerosol layers lower the upward flux at the surface both in the TD $\left(-20\right.$ to $\left.-30 \mathrm{~W} / \mathrm{m}^{2}\right)$ and, more weakly, in the GP $(0$ to $-20 \mathrm{~W} / \mathrm{m}^{2}$ ). The high total values above the high albedo surfaces of the TD apparently leave more room for variation due to aerosol absorption. Aerosol presence increases the upward flux at the TOA in both regions due to reflection. It is similar in magnitude (around $+25 \mathrm{~W} / \mathrm{m}^{2}$ ), though more varying above the GP.

Dust has a comparably strong influence on LW fluxes and heating rates as it has in the SW spectral range. In Fig. 5b, we see the aerosol influence on the simulated LW fluxes. In these thermal infrared wavelengths, the earth is simulated to be the only source of radiation. Not simulated is LW radiation emitted by the sun, which is negligible in magnitude when the troposphere is considered. Thus, the downward LW flux at the TOA remains zero with or without aerosol layers below. The downward LW flux at the surface increases when aerosols are present as the upwelling LW radiation is partly re-emitted back to the surface. The increase in downward flux at the surface is strongly dependent on aerosol concentrations; it reaches $+20 \mathrm{~W} / \mathrm{m}^{2}$ above the TD and $+10 \mathrm{~W} / \mathrm{m}^{2}$ above the GP. In contrast, the upward LW flux at the TOA is reduced by the presence of aerosols due to the same effect and by a similar amount.

The overall effect of aerosols on both SW and LW fluxes combined, shown in Fig. 5c, is a reduction by around 60 to up to $90 \mathrm{~W} / \mathrm{m}^{2}$ at the surface. The net effect at the TOA is mostly an increase in upward flux, i.e. outgoing radiation, while the downward flux remains unaltered. Thus, the aerosols in this particular simulation cool the system. This effect is especially pronounced above the GP.

A closer look at the heating rates, shown in Fig. 6, gives more insights into where in the atmosphere the actual absorption is happening. The strongest SW heating of up to $2 \mathrm{~K}$ /day is located at around $5 \mathrm{~km}$ a.m.s.l. in the TD and somewhat lower, at 4 to $5 \mathrm{~km}$ a.m.s.l., in the GP. In a given aerosol layer, the heating is simulated to be strongest on the upper edge. On the one hand, this behavior is physically correct, as the incoming solar radiation at higher altitudes is stronger. On the other hand, the magnitude of this effect might be overestimated. This is due to the measurement technique of CALIPSO: for each aerosol layer, regardless of its vertical extent, the CALIPSO algorithms calculate only one integrated AOD value with assumed vertically homogeneous aerosol distributions. A more realistic scenario would be a varying distribution of aerosol concentration with highest 
(a)

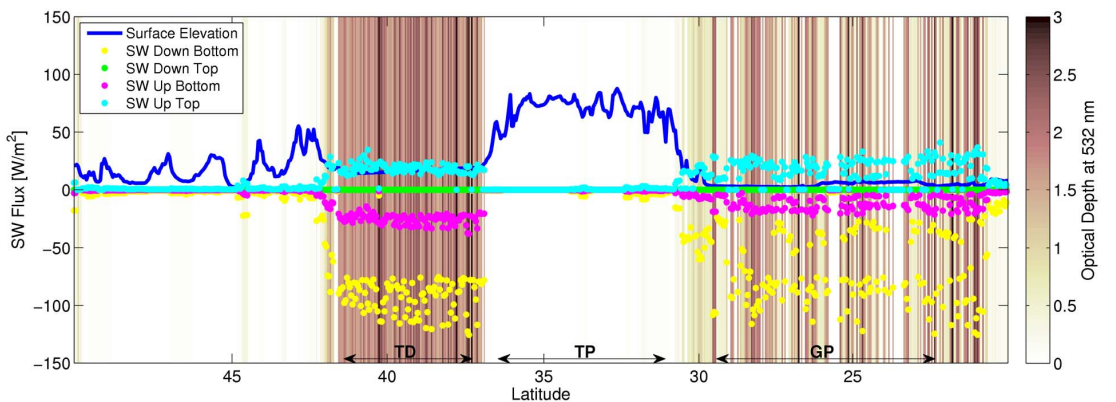

(b)

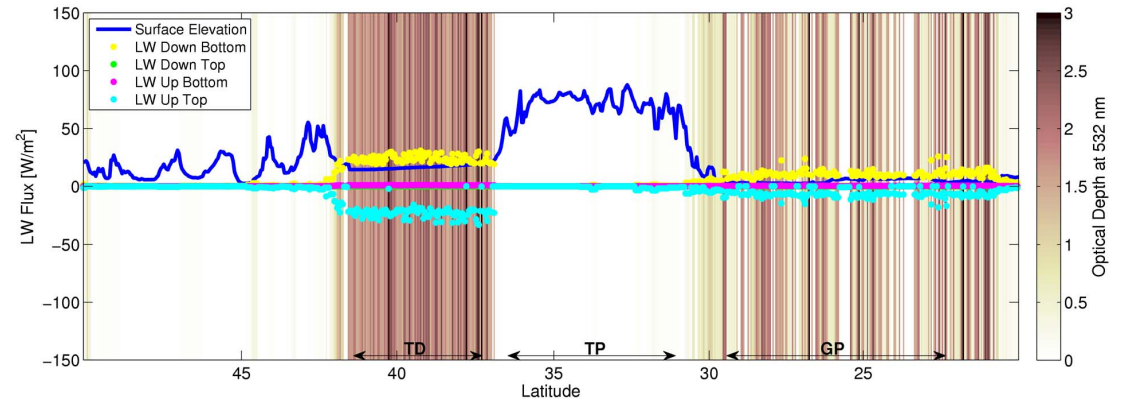

(c)

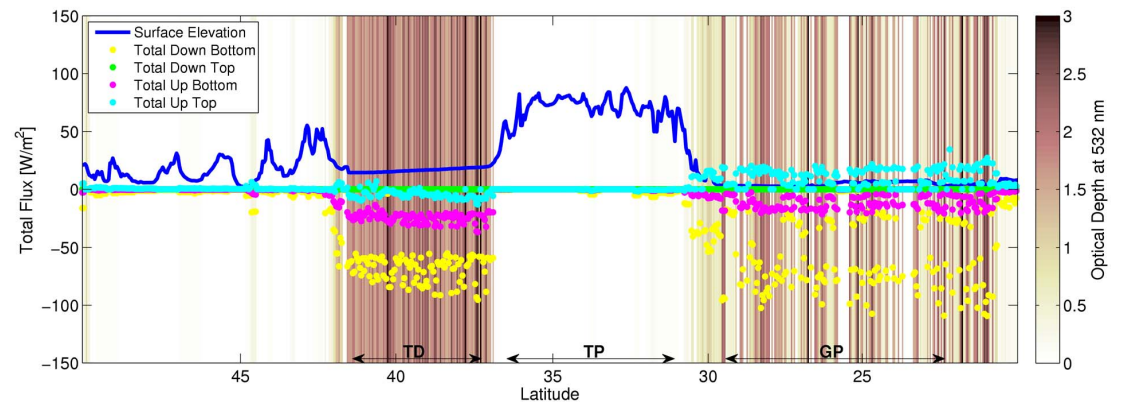

Fig. 5. Anomalies in (a) SW, (b) LW, and (c) Total (SW+LW) fluxes induced by aerosols at the top (50 km a.m.s.1.) and bottom (0 km a.m.s.1.) of the modeled atmosphere in both upward and downward directions. The background shading indicates the AOD at $532 \mathrm{~nm}$ as measured by CALIPSO. MODIS surface albedo values and CALIPSO aerosol distributions are used as input. Approximate extensions of the TD, TP, and GP regions are marked on the $\mathrm{x}$-axis.

values close to the sources, i.e. close to the ground. A distribution of this kind might reduce the simulated effect of enhanced elevated heating apparent in Fig. 6a. However, elevated aerosols often form vertically rather uniform layers, which frequently are also relatively thin. Thus, as far as the simulations for this study approximate reality, higher parts of the aerosol layers show a twofold increase in heating in relation to their vertical position only. Note that the optically thin aerosol layers above the TP produce only little heating of $0.2 \mathrm{~K} /$ day and less even for this case with relatively heavy aerosol load. Cooling of lower atmospheric layers due to dimming by aerosols is apparent, but with $-0.2 \mathrm{~K} /$ day equally small.

The heating rates due to LW absorption by aerosol layers are shown in Fig. 6b. The aerosols above the TD and, less pronounced, above the GP, cool the higher atmospheric layers by absorbing and reflecting $\mathrm{LW}$ radiation coming from the surface. Above the TD, this effect reaches -1 to $-2 \mathrm{~K} /$ day, while in the GP it is limited to -0.5 to
$-1 \mathrm{~K} /$ day. Near-surface regions particularly in the TD are heated $(+1 \mathrm{~K} /$ day $)$ by aerosols absorbing LW radiation. It is instructive to compare the heating rates in the LW with those simulated in the SW (Fig. 6a). While SW heating occurs throughout the vertical extent of the aerosol layers and is strongest in the upper parts, LW radiation cools these upper parts and slightly heats the lower parts.

The SW heating is generally stronger than the LW cooling, creating a positive overall effect on the atmosphere, shown in Fig. 6c. The distribution of heating throughout an aerosol layer shows a maximum at the bottom for strongest combined SW and LW heating in the TD; in the GP, the heating is more evenly distributed vertically.

\subsection{Albedo effects on heating rates}

A central assumption in the EHP hypothesis by Lau et al. (2006) was the enhancement of the direct aerosol effect by a high albedo of the underlying surface. In order to quantify 
(a)

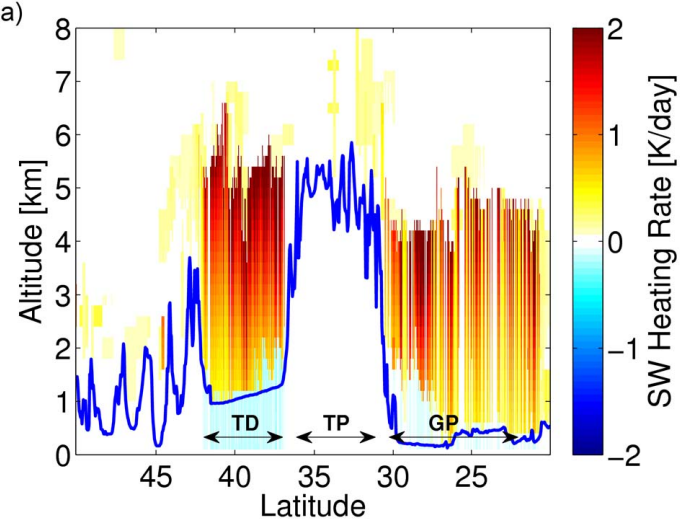

(b)

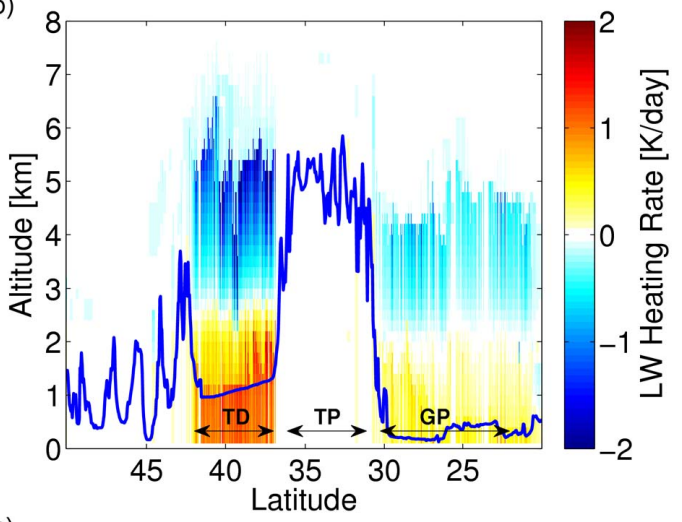

(c)

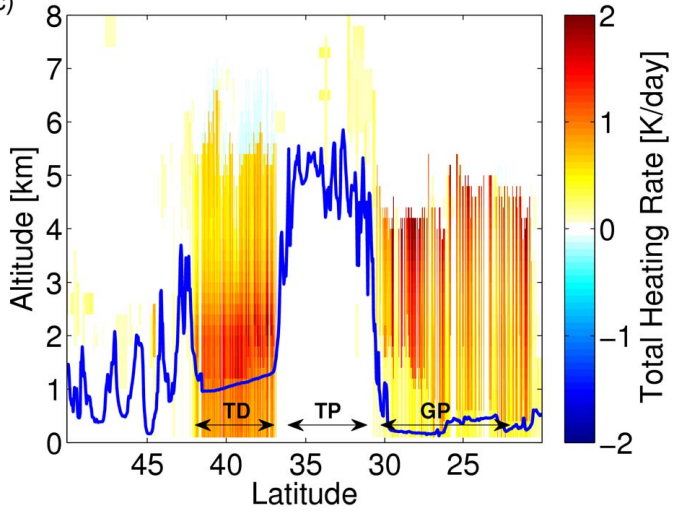

Fig. 6. Anomalies in (a) SW, (b) LW, and (c) Total (SW+LW) heating rates induced by aerosols throughout the vertical extent of the atmosphere in K/day. MODIS surface albedo values and CALIPSO aerosol distributions are used as input.

the effect of albedo on aerosol forcing, Eq. (1) has to be modified towards

$$
\begin{aligned}
\Delta_{\mathrm{alb}} & =\left[\left(\frac{\partial T}{\partial t}\right)_{\mathrm{AA}}-\left(\frac{\partial T}{\partial t}\right)_{\mathrm{NA}}\right]_{\mathrm{MODIS}} \\
& -\left[\left(\frac{\partial T}{\partial t}\right)_{\mathrm{AA}}-\left(\frac{\partial T}{\partial t}\right)_{\mathrm{NA}}\right]_{\mathrm{const}},
\end{aligned}
$$

where - as above - the heating rates are calculated in simulations with either all aerosols (AA) or no aerosols (NA) included. Furthermore, the simulations are driven with ei- ther the satellite-derived albedo (MODIS) or a fixed typical value (const). This way of calculating the anomalies allows to separate the albedo-induced anomalies due to aerosols from the albedo-induced anomalies that occur even in an aerosol-free atmosphere due to molecular scattering. A simple calculation of $\left(\frac{\partial T}{\partial t}\right)_{\mathrm{AA}, \mathrm{MODIS}}-\left(\frac{\partial T}{\partial t}\right)_{\mathrm{AA}, \mathrm{const}}$ would comprise the latter effects, Eq. (2) does not.

The plot of $\Delta_{\text {alb }}$ for the SW heating rates in Fig. 7 displays the increased aerosol heating due to albedo effects above the TD and a smaller effect in the same direction above the GP. Aerosol heating above the TD is enhanced by $0.1 \mathrm{~K} /$ day close to the surface and by $0.06 \mathrm{~K} /$ day at the top of the layers between 5 and $6 \mathrm{~km}$. The increased heating above the GP generally remains close to $0.02 \mathrm{~K} /$ day in lower layers; it mixes with slight cooling above that level. On top of the TP, the signal remains close to zero - the high surface albedo does not produce enhanced heating, as the present aerosol layers are too thin.

Comparing Fig. 7 to Fig. 6a, a first estimate is that the higher albedo in desert areas contributes to SW aerosol heating with around $10 \%$. The heating enhancement is more pronounced in lower aerosol layers, i.e. close to the surface that produces the effect. A bright surface additionally heats the aerosol layer from below.

\subsection{Regional and seasonal aerosol radiative effects}

The above case study does not show elevated heating in particular, but this might also be due to an unlucky hand in choosing a particular day. Therefore, we processed the entire CALIPSO dataset for MAM 2007, 2008, and 2009 with the method described in Sect. 5.2. We have performed three model runs: the first run was driven by CALIPSO satellite data on aerosol distributions, the surface albedo was fixed to the values given in Table 1, i.e. to the proposed values for land surfaces implemented in the RTM; the second run used the same aerosol distributions, but the values for the surface albedo in the visible wavelengths were prescribed by MODIS satellite data; the third run simulated an aerosol-free atmosphere, yet the MODIS albedo values were used. The third run is therefore the control run which the second run is normalized with in order to account for aerosol effects only.

First, let us consider the regional distribution of the seasonal-average downward SW fluxes (Fig. 8). The aerosolinduced anomalies in downward SW fluxes follow from scattering and absorption of solar radiation in all layers above the level considered in the respective map. At $5 \mathrm{~km}$ (Fig. 8a), the absorption and reflection of higher aerosol layers have reduced the downwelling sunlight by up to $2 \mathrm{~W} / \mathrm{m}^{2}$ locally. Already at this altitude - above most of the Himalayan mountains - the TD and the Thar Desert are the most prominent regions for SW absorption due to dust while aerosols in the higher tropospheric layers above India, China, and the TP only reduce solar irradiation by around $0.5 \mathrm{~W} / \mathrm{m}^{2}$. 


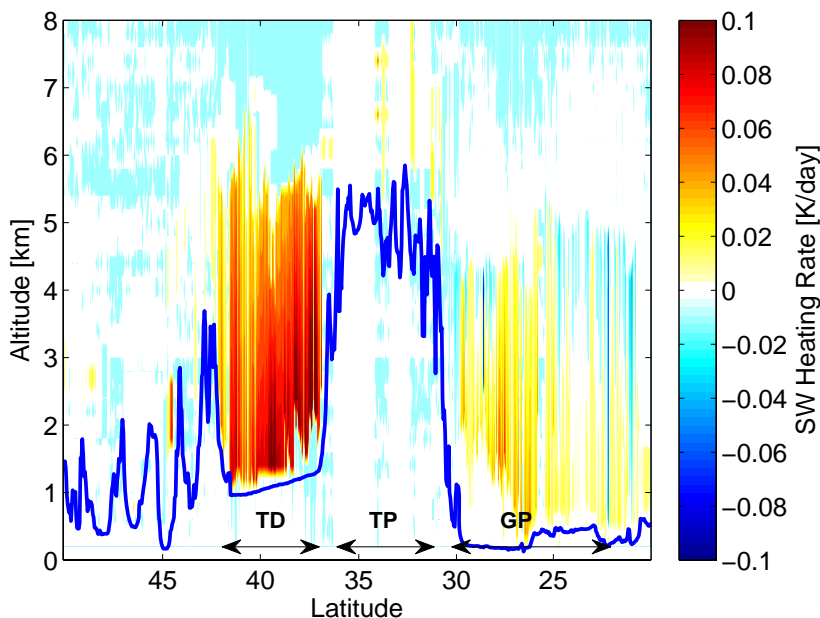

Fig. 7. Effect of albedo variations on aerosol forcing $\left(\Delta_{\mathrm{alb}}\right)$ in SW heating rates throughout the vertical extent of the atmosphere in K/day.

The reduction in SW flux at surface level (Fig. 8b) shows a more pronounced pattern. There are two clear minima in the TD and the IP/GP regions. Furthermore, a minimum solar irradiation is located above the area around Beijing and Shanghai in China, yet these aerosols cannot contribute to TP warming as shown in Fig. 3. In the three regions of strongest dimming mentioned, the model computes SW flux anomalies of around -20 to $-30 \mathrm{~W} / \mathrm{m}^{2}$, hence of an order of magnitude larger than anywhere in the upper troposphere.

In the next step, we study the SW heating rates due to aerosols shown in Fig. 9. We divide the atmosphere in an upper and a lower layer. The border between the two layers is set at $5 \mathrm{~km}$ a.m.s.l., the approximate mean surface elevation of the TP. The atmospheric heating results solely from sunlight absorption by aerosols, but it may be reinforced by reflection from lower-lying features - either reflecting aerosols, air molecules, or the ground. The distribution of upper layer heating (Fig. 9a) is close to the distribution of solar dimming shown in Fig. 8a with the highest values above the TD and the IP/GP and lower values above the TP and India. The TD's prominence in Fig. 9a is an indication that the homogeneous lower-lying reflecting dust layers of the TD boost the heating of higher atmospheric layers stronger than the highalbedo surfaces of the Himalayan slopes or the TP do. The TP's role in reinforcing aerosol heating and thereby increasing monsoonal circulation might therefore be less important than previously thought. The maximum upper tropospheric heating between $90^{\circ} \mathrm{E}$ and $110^{\circ} \mathrm{E}$ probably results from TD dust outflow transported by upper-level westerlies.

The distribution of lower level heating (Fig. 9b), again, is close to the distribution of solar dimming shown in Fig. 8b. Thick aerosol layers above most of India and the TD produce seasonal mean heating rates of between 0.2 and $0.3 \mathrm{~K} /$ day: 5 to 10 times more than those in the upper atmosphere. The

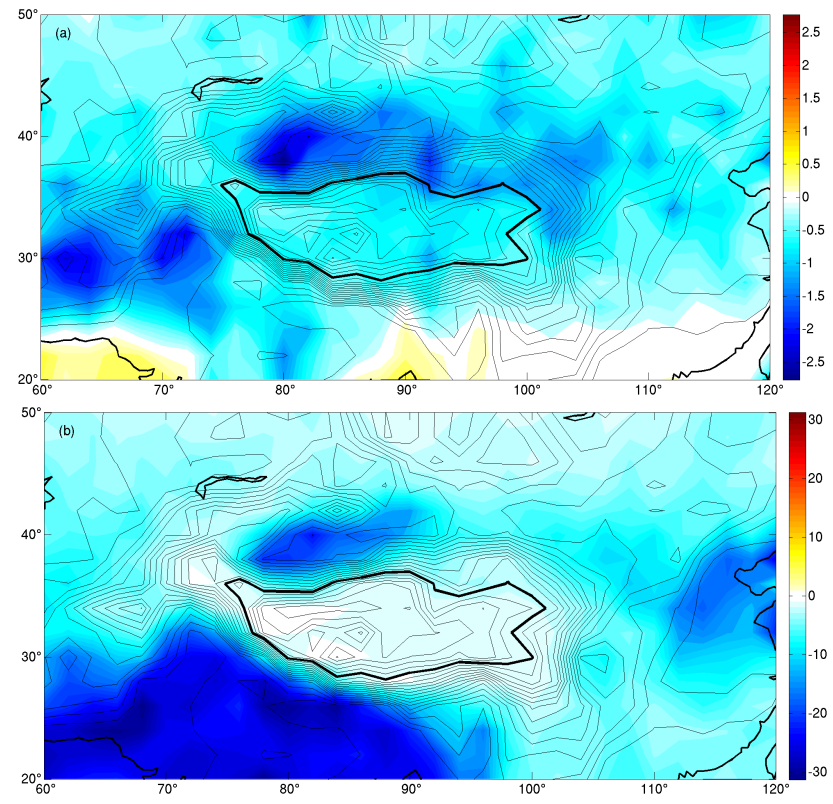

Fig. 8. Downward SW fluxes anomalies due to aerosols at (a) $5 \mathrm{~km}$ and (b) $0 \mathrm{~km}$ a.m.s.l. in $\mathrm{W} / \mathrm{m}^{2}$. Simulation with MODIS surface albedo. Note the different scalings of the colorbars, each time adjusted to the respective extreme value. The thick lines indicate coasts and the Tibetan Plateau.

eastern and western surroundings of the TP are less polluted, but the aerosols still produce heating rates in the lower atmosphere of around $0.05 \mathrm{~K} /$ day.

\subsection{Combination of $L W$ and $S W$ aerosol effects: total fluxes and heating rates}

To answer the question of whether aerosols locally heat the atmosphere and how strong this heating is, it is, after all, in the temporal mean irrelevant in what spectral bands this heating occurs. In the previous sections, we have seen that radiative effects in the LW are at least comparable in magnitude and location to SW effects, although sometimes of opposite sign. Therefore, it is important to add up both SW and LW effects and to look at total fluxes and heating rates. Figure 10 shows the resulting total heating rates, vertically averaged over the entire atmospheric column. Heating above the TD and above northern India is similar in magnitude with values ranging between 0.1 and $0.15 \mathrm{~K} /$ day. All other areas surrounding the TP display lower but positive heating rates close to $0.05 \mathrm{~K} /$ day. On the southern and northern slopes of the TP, heating rates decrease with increasing surface elevation. The TP itself is, in comparison to other regions, virtually unaffected by heating. As for direct aerosol effects influencing the Asian Summer Monsoon, the dust and pollution plumes above India are therefore more meaningful than those above the TP. 


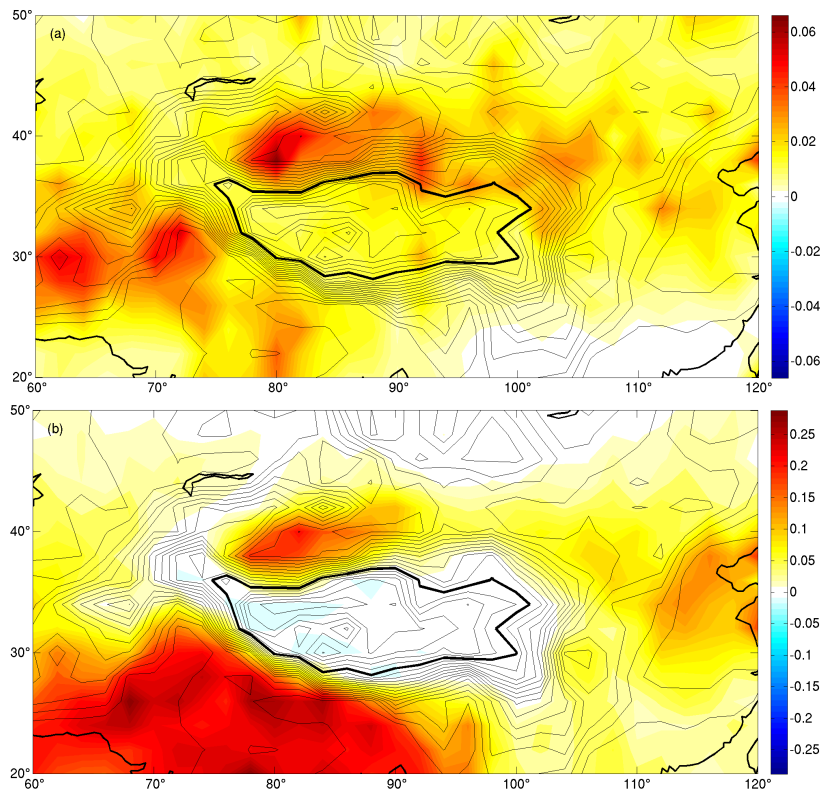

Fig. 9. Vertically averaged SW heating rate anomalies due to aerosols between (a) 5 and $8 \mathrm{~km}$ and (b) 0 and $5 \mathrm{~km}$ a.m.s.l. in K/day. Simulation with MODIS surface albedo. Note the different scalings of the colorbars, each time adjusted to the respective extreme value. The thick lines indicate coasts and the Tibetan Plateau.

\subsection{Vertical distribution of aerosol-induced heating}

The previous inquiries prove the ROI strongly heterogeneous, but the different subregions defined in Fig. 1 repeatedly show up as areas of strongest - or weakest - effects in aerosol concentration and, consequently, radiative impact. Therefore, averaging over each of these regions should not constitute a major error but give a statistically reliable picture of where in the atmospheric column heating and cooling is occurring. Fig. 11 shows the vertical distributions of heating rates in the SW and LW spectral regions separately as well as their combination to a total heating rate. The overall situation in the ROI (Fig. 11a) is one of SW heating occurring between 0 and $6 \mathrm{~km}$ with the highest values of close to $0.1 \mathrm{~K} /$ day between 2 and $3 \mathrm{~km}$. LW heating occurs in the lower $1.5 \mathrm{~km}$ of the atmosphere, whereas higher layers are exposed to LW cooling. This effect reaches its maximum at $3 \mathrm{~km}$. LW heating and cooling effects are smaller in magnitude by at least a factor of 2 throughout the atmospheric column. The total result is therefore a net heating at all altitudes, strongest between the surface and $3 \mathrm{~km}$.

The interannual variability is close to what we noted for dust variability in Sect. 3: effects south of the TP are stronger in 2008, while north of the TP they are weaker in that year. The variability stays below $\pm 0.03 \mathrm{~K} /$ day.

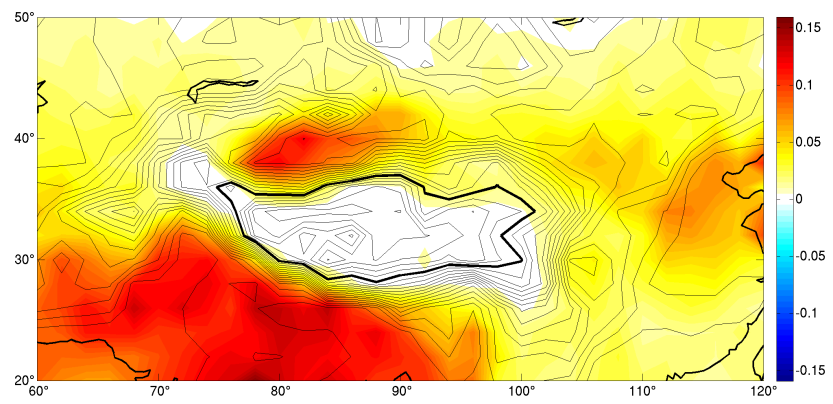

Fig. 10. Vertically averaged total heating rate anomalies due to aerosols between 0 and $8 \mathrm{~km}$ a.m.s.l. in K/day. Simulation with MODIS surface albedo. The thick lines indicate coasts and the Tibetan Plateau.

\subsection{Albedo effects on fluxes and heating rates}

Aerosol-induced heating of the atmosphere is strongest above strongly reflecting surfaces (Haywood and Boucher, 2000). In the ROI of this study, the Taklamakan Desert, the Thar Desert, and parts of the Tibetan Plateau show high albedo values, therefore aerosol effects in these regions should be reinforced. It is the aim of this section to examine the extent to which this is happening.

We calculate the effect of albedo variations on aerosol forcing, in the following referred to as $\Delta_{\text {alb}}$, with Eq. (2). $\Delta_{\text {alb }}$ can be calculated for fluxes and for heating rates, both in the SW and in the LW. Yet, the albedo effect in the LW is negligible as only the SW albedo is varied in the simulations. Therefore, we do not separate the different spectral regions in the following, rather, we only show results for total heating rates.

Figure 12 shows $\Delta_{\mathrm{alb}}$ for total heating rates. Between 0 and $5 \mathrm{~km}$ a.m.s.l. (Fig. 12a), there are two regions of major aerosol heating enhancement by high albedo values: the TD and the IP with the Thar Desert. The Middle East, the Gobi Desert, and most of India is affected to a smaller extent. The latter indicates that the surface albedo is generally underestimated by the model's standard land surface values.

The effect of additional heating in the lower atmosphere is strongest in the IP and the TD, however it does not exceed $0.02 \mathrm{~K} /$ day. Thus, albedo effects are responsible for not more than $10 \%$ of the SW heating estimated for the lower $5 \mathrm{~km}$ above the TD in Fig. 9b. Negative anomalies exist above the oceans, where aerosol heating shrinks by around $0.01 \mathrm{~K} /$ day.

Between 5 and $8 \mathrm{~km}$ (Fig. 12b), $\Delta_{\text {alb }}$ generally remains below $0.003 \mathrm{~K} /$ day. The strongest additional heating is found above the TD and towards the Gobi Desert. In other regions, the signal is smaller still, attaining no more than $0.002 \mathrm{~K} /$ day.

The effect of a spatially varying albedo on heating rates is therefore modelled as predicted with positive values for $\Delta_{\text {alb }}$ particularly above bright surfaces such as deserts and the TP. The quantitative analysis shows us however that the effect is quite small compared to the total aerosol-induced heating. 
(a)

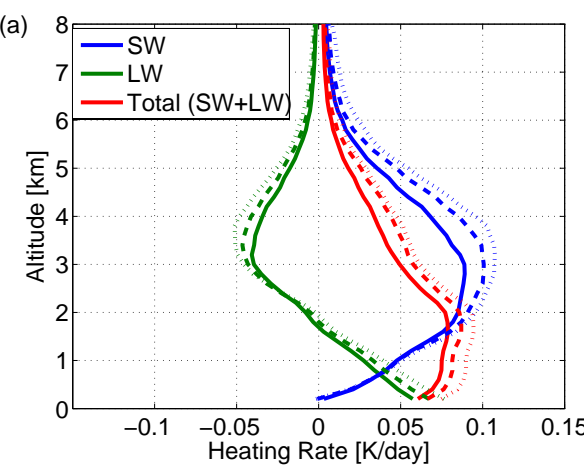

(c)

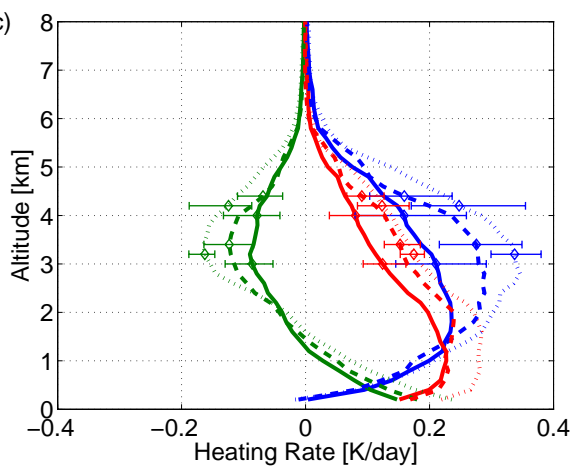

(e)

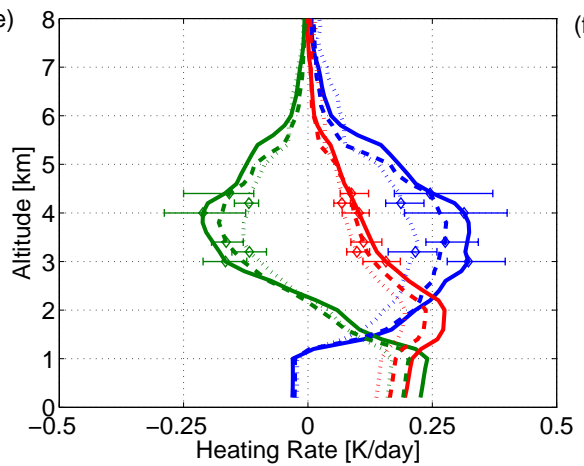

(b)

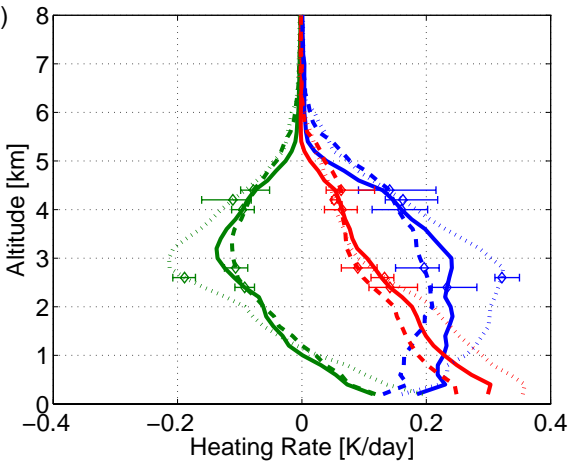

(d)

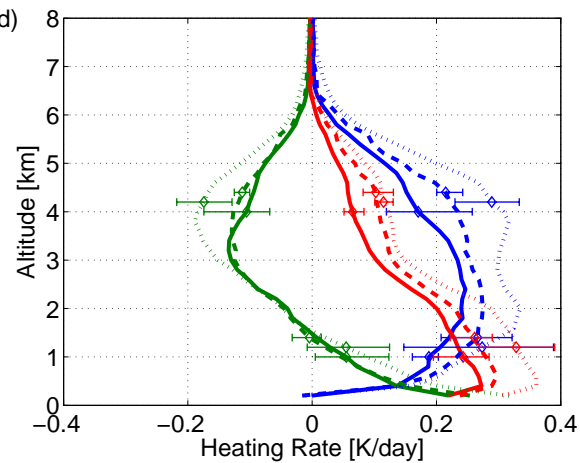

(f)

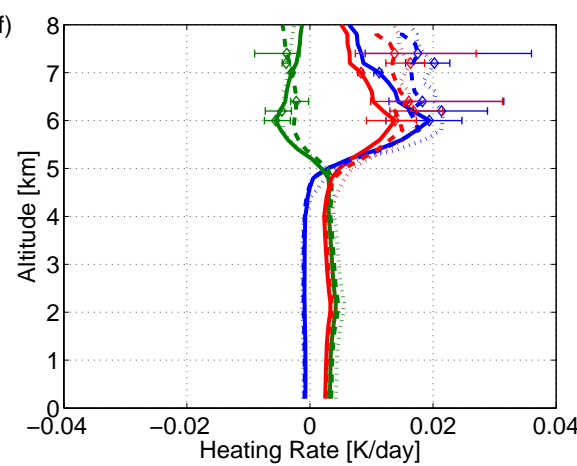

Fig. 11. Vertical distribution of the heating rates in K/day due to SW radiation (blue lines), LW radiation (green lines), and total radiation (red lines) in (a) the entire region of interest, (b) the Arabian Sea, (c) the Ganges Plains, (d) the Indus Plains, (e) the Taklamakan Desert, and (f) the Tibetan Plateau. Simulation with MODIS surface albedo. Note the different scalings of the respective x-axis. Data displayed separately for MAM 2007 (solid lines), 2008 (dotted lines), and 2009 (dashed lines).

Increased monsoonal circulation due to aerosol heating is therefore more likely to occur above the IP and GP than above the Himalayan slopes.

\section{Summary and conclusions}

Satellite observations are a useful tool to assess aerosol impacts on the Asian Summer Monsoon. The quantification and localization of aerosol occurrence above and around the Tibetan Plateau and their use as input data for a radiative transfer model help to evaluate theories that have circulated in the scientific community for several years and were for the most part based on general circulation model (GCM) simulations only.

CALIPSO lidar satellite data of MAM 2007, 2008, and 2009 should close gap in our knowledge about vertical aerosol distribution. The dataset delivers meaningful horizontal and vertical distributions of different aerosol types in the ROI. Pure dust is the most prominent aerosol type north of the Tibetan Plateau. It originates from the Taklamakan Desert, a sparsely populated desert in western China. Contrarily, the air above India and the adjacent oceans is strongly contaminated with polluted dust. It is a mixture of dust from the Thar Desert in the Indus Plains, advected dust from the Arabian Sea and the Middle East, and pollution 


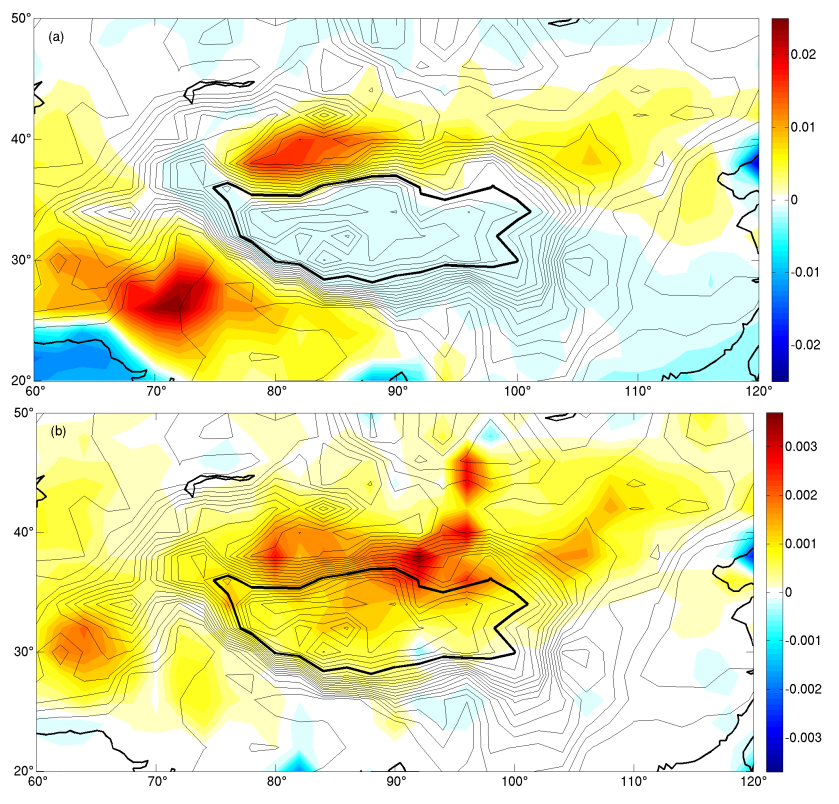

Fig. 12. Effect of albedo variations on aerosol forcing $\left(\Delta_{\mathrm{alb}}\right)$ in vertically averaged total heating rates between (a) 0 and $5 \mathrm{~km}$ and (b) 5 and $8 \mathrm{~km}$ a.m.s.l. in K/day. Note the different scalings of the colorbars, each time adjusted to the respective extreme value. The thick lines indicate coasts and the Tibetan Plateau.

from Indian megacities. The aerosol distribution throughout the ROI emerges as highly heterogeneous.

CALIPSO observations of the vertical aerosol distribution show that the bulk of the aerosol is concentrated in the lower $5 \mathrm{~km}$ of the atmosphere. The $5-\mathrm{km}$ limit is crucial to the possibility of cross-Tibetan Plateau dust transport. Computations of zonal mean vertical profiles comprising the entire ROI - a common method used in much of the previous literature - turn out to be of limited use due to the irregular shapes of source regions and topographical features.

The embedding of reanalysis wind data allows to assess possible pathways of aerosol transport. While the typical monsoon pattern of near-surface south-westerlies above the Arabian Sea arises in June, higher-level westerlies dominate during the pre-monsoon season. On the basis of this observation and its combination with aerosol data, we identify four putative source regions for aerosols that might influence the Asian Summer Monsoon via radiative effects: the Arabian Sea, the Indus Plains, the Ganges Plains, and the Taklamakan Desert. Contrarily, aerosols from major source regions such as the Gobi Desert and the Beijing/Shanghai area are transported away from the monsoon region.

Radiative transfer model calculations of their direct effects prove aerosols in the ROI to have a sizable impact on the earth's radiative budget, i.e. on fluxes and heating rates in the shortwave (SW) and the longwave (LW) spectral regions. A case study of 14 May 2007, a day with exceptionally high aerosol loading around the Tibetan Plateau, reveals SW ra- diative impacts to be most decisive. The aerosols reflect and absorb enough sunlight to reduce surface irradiation by one third. The absorption occurs particularly in the upper parts of the aerosol layers, counterbalanced to some extent by the aerosol's role as insulators in the LW. Heating rates locally reach $1.5 \mathrm{~K} /$ day. Higher surface albedos increase the heating effect by producing multiple reflections between the surface and the aerosols.

A study of the direct aerosol effects throughout the ROI in MAM 2007, 2008, and 2009 yields an estimated seasonal average SW flux reduction at the surface in the monsoon region of between 20 and $30 \mathrm{~W} / \mathrm{m}^{2}$. This compares well with the $8 \%$ reduction that Ramanathan et al. (2005) calculated. The aerosols heat the lower atmosphere in the SW by 0.2 to $0.3 \mathrm{~K} /$ day in India and the Taklamakan Desert. This heating is about twice as strong as what Wang et al. (2009) simulated for the lower atmosphere. However, when comparing our results to the their study, note that Wang et al. (2009) accounted for anthropogenic aerosols only, thereby neglecting the most prominent aerosol in the region: dust.

A large elevated heating, particularly above the Tibetan Plateau, is absent in our results. SW heating above the Tibetan Plateau does not exceed $0.05 \mathrm{~K} /$ day in the seasonal mean and is thus considerably weaker than in the surrounding regions. In our simulations, the Himalayan slopes do not emerge as regions of particularly strong heating. This result stands in contrast to the Elevated Heat Pump (EHP) hypothesis by Lau et al. (2006) who simulated SW heating of between 0.2 and $0.4 \mathrm{~K} /$ day above the Tibetan Plateau.

The combined SW and LW direct effect of the aerosol plumes is an average heating of 0.1 to $0.15 \mathrm{~K} /$ day throughout the lower $8 \mathrm{~km}$ of the atmosphere in both India and the Taklamakan Desert. The aerosols hence re-distribute energy from the surface towards the lower troposphere. Vertical profiles of heating rate anomalies show that the total heating effect is mostly located in the lower $3 \mathrm{~km}$ of the atmospheric column, with small interannual variations that prove the robustness of the presented results. The model study that led to the EHP hypothesis localized aerosol-induced heating rates inaccurately and overestimated them by omitting LW effects.

The quantification of the role of varying surface albedo values in aerosol heating reveals that an intensified heating above bright surfaces is manifest. Nevertheless, the effect is unable to increase heating rates above the Tibetan Plateau vigorously enough to compensate for the low aerosol concentrations in this region. Albedo effects amplify aerosolinduced heating rates by $10 \%$ at most.

Acknowledgements. CALIPSO data were obtained from the NASA Langley Research Center Atmospheric Science Data Center; NCEP Reanalysis Derived data were provided by the NOAA/OAR/ESRL PSD, Boulder, Colorado, USA; MODIS albedo data were made available by the MODIS Atmosphere project at NASA Goddard Space Flight Center. We are grateful to Stefan Kinne, MPI, Germany, for his help in the application of his radiative transfer model. 
We also wish to thank Abhay Devasthale, SMHI, Sweden, and Claus Goessling, TU Dortmund, Germany, for their valuable ideas that improved this work. Finally, we appreciated the constructive comments that two anonymous reviewers gave on an earlier draft of this paper.

The service charges for this open access publication have been covered by the Max Planck Society.

Edited by: Y. Balkanski

\section{References}

Bollasina, M., Nigam, S., and Lau, K. M.: Absorbing Aerosols and Summer Monsoon Evolution over South Asia: An Observational Portrayal, J. Climate, 21, 3221-3239, 2008.

Chung , C. E., Ramanathan, V., Kim, D., and Podgorny, I. A.: Global anthropogenic aerosol direct forcing derived from satellite and ground-based observations, J. Geophys. Res., 110, D24207, doi:10.1029/2005JD006356, 2005.

Collier, J. C. and Zhang, G. J.: Aerosol direct forcing of the summer Indian monsoon as simulated by the NCAR CAM3, Clim. Dynam., 32, 313-332, 2009.

Eguchi, K., Uno, I., Yumimoto, K., Takemura, T., Shimizu, A., Sugimoto, N., and Liu, Z.: Trans-pacific dust transport: integrated analysis of NASA/CALIPSO and a global aerosol transport model, Atmos. Chem. Phys., 9, 3137-3145, doi:10.5194/acp-93137-2009, 2009.

Forster, P., Ramaswamy, V., Artaxo, P., Berntsen, T., Betts, R., Fahey, D. W., Haywood, J., Lean, J., Lowe, D. C., Myhre, G., Nganga, J., Prinn, R., Raga, G., Schulz, M., and Van Dorland, R.: Changes in Atmospheric Constituents and in Radiative Forcing, in: Climate Change 2007 - The Physical Science Basis. Contribution of Working Group I to the Fourth Assessment Report of the IPCC, edited by: Solomon, S., Qin, D., Manning, M., Chen, Z., Marquis, M., Averyt, K. B., Tignor, M., and Miller, H. L., Cambridge University Press, 129-234, 2007.

Gautam, R., Hsu, N. C., Lau, K. M., Tsay, S. C., and Kafatos, M.: Enhanced pre-monsoon warming over the Himalayan-Gangetic region from 1979 to 2007, Geophys. Res. Lett., 36, L07704, doi:10.1029/2009GL037641, 2009a.

Gautam, R., Liu, Z., Singh, R. P., and Hsu, N. C.: Two contrasting dust-dominant periods over India observed from MODIS and CALIPSO data, Geophys. Res. Lett., 36, L06813, doi:10.1029/2008GL036967, 2009b.

Gustafsson, O., Krusa, M., Zencak, Z., Sheesley, R. J., Granat, L., Engstrom, E., Praveen, P. S., Rao, P. S. P., Leck, C., and Rodhe, H.: Brown Clouds over South Asia: Biomass or Fossil Fuel Combustion?, Science, 323, 495-498, 2009.

Hara, Y., Uno, I., Yumimoto, K., Tanaka, M., Shimizu, A., Sugimoto, N., and Liu, Z.: Summertime Taklimakan dust structure, Geophys. Res. Lett., 35, L23801, doi:10.1029/2008GL035630, 2008.

Haywood, J. and Boucher, O.: Estimates of the Direct and Indirect Radiative Forcing Due to Tropospheric Aerosols: A Review, Rev. Geophys., 38, 513-543, 2000.

Huang, J., Minnis, P., Yi, Y., Tang, Q., Wang, X., Hu, Y., Liu, Z., Ayers, K., Trepte, C., and Winker, D.: Summer dust aerosols detected from CALIPSO over the Tibetan Plateau, Geophys. Res. Lett., 34, L18805, doi:10.1029/2007GL029938, 2007.

Huang, J., Minnis, P., Chen, B., Huang, Z., Liu, Z., Zhao, Q., Yi, Y., and Ayers, J. K.: Long-range transport and vertical structure of Asian dust from CALIPSO and surface measurements during PACDEX, J. Geophys. Res.-Atmos., 113, D23212, doi:10.1029/2008JD010620, 2008.

Huang, J., Fu, Q., Su, J., Tang, Q., Minnis, P., Hu, Y., Yi, Y., and Zhao, Q.: Taklimakan dust aerosol radiative heating derived from CALIPSO observations using the Fu-Liou radiation model with CERES constraints, Atmos. Chem. Phys., 9, 4011-4021, doi:10.5194/acp-9-4011-2009, 2009.

Kaufman, Y. J., Tanre, D., and Boucher, O.: A satellite view of aerosols in the climate system, Nature, 419, 215-223, 2002.

Kistler, R., Kalnay, E., Collins, W., Saha, S., White, G., Woollen, J., Chelliah, M., Ebisuzaki, W., Kanamitsu, M., Kousky, V., van den Dool, H., Jenne, R., and Fiorino, M.: The NCEP-NCAR 50-Year Reanalysis: Monthly Means CD-ROM and Documentation, B. Am. Meteor. Soc., 82, 247-267, 2001.

Lau, K. M. and Kim, K. M.: Observational relationships between aerosol and Asian monsoon rainfall, and circulation, Geophys. Res. Lett., 33, L21810, doi:10.1029/2006GL027546, 2006.

Lau, K. M., Kim, M. K., and Kim, K. M.: Asian summer monsoon anomalies induced by aerosol direct forcing: the role of the Tibetan Plateau, Clim. Dynam., 26, 855-864, 2006.

Lau, K. M., Ramanathan, V., Wu, G. X., Li, Z., Tsay, S. C., Hsu, C., Sikka, R., Holben, B., Lu, D., Tartari, G., Chin, M., Koudelova, P., Chen, H., Ma, Y., Huang, J., Taniguchi, K., and Zhang, R.: The Joint Aerosol-Monsoon Experiment, B. Am. Meteor. Soc., 89, 369-383, 2008.

Lelieveld, J., Crutzen, P. J., Ramanathan, V., Andreae, M. O., Brenninkmeijer, C. A. M., Campos, T., Cass, G. R., Dickerson, R. R., Fischer, H., de Gouw, J. A., Hansel, A., Jefferson, A., Kley, D., de Laat, A. T. J., Lal, S., Lawrence, M. G., Lobert, J. M., Mayol-Bracero, O. L., Mitra, A. P., Novakov, T., Oltmans, S. J., Prather, K. A., Reiner, T., Rodhe, H., Scheeren, H. A., Sikka, D., and Williams, J.: The Indian Ocean Experiment: Widespread Air Pollution from South and Southeast Asia, Science, 291, 5506, doi:10.1126/science.1057103, 2001.

Lin, S. J., Atlas, R., and Yeh, K. S.: Global Weather Prediction and High-End Computing at NASA, Comput. Sci. Eng., 6, 29-35, 2004.

Liu, D., Wang, Z., Liu, Z., Winker, D., and Trepte, C.: A height resolved global view of dust aerosols from the first year CALIPSO lidar measurements, J. Geophys. Res., 113, D16214, doi::10.1029/2007JD009776, 2008.

Liu, Z., Omar, A. H., Hu, Y., Vaughan, M. A., and Winker, D. M.: CALIOP Algorithm Theoretical Basis Document, Part 3: Scene Classification Algorithms, NASA Langley Research Center, http://www-calipso.larc.nasa.gov/resources/pdfs/ PC-SCI-202_Part3_v1.0.pdf, last access: 17 February 2010, 2005.

Liu, Z., Liu, D., Huang, J., Vaughan, M., Uno, I., Sugimoto, N., Kittaka, C., Trepte, C., Wang, Z., Hostetler, C., and Winker, D.: Airborne dust distributions over the Tibetan Plateau and surrounding areas derived from the first year of CALIPSO lidar observations, Atmos. Chem. Phys., 8, 5045-5060, doi:10.5194/acp-85045-2008, 2008.

Meehl, G. A., Arblaster, J. M., and Collins, W. D.: Effects of Black 
Carbon Aerosols on the Indian Monsoon, J. Climate, 21, 28692882, 2008.

Menon, S., Hansen, J., Nazarenko, L., and Luo, Y.: Climate effects of black carbon aerosols in China and India, Science, 297, 22502253, 2002.

Omar, A. H., Winker, D., and Won, J.-G.: Aerosol models for the CALIPSO lidar inversion algorithms, Soc. Photo-Opt. Instru., 5240, 153-164, doi:10.1117/12.511067, 2004.

Pease, P. P., Tchakerian, V. P., and Tindale, N. W.: Aerosols over the Arabian Sea: geochemistry and source areas for aeolian desert dust, J. Arid Environ., 39, 477-496, 1998.

Ramanathan, V. and Carmichael, G.: Global and regional climate changes due to black carbon, Nat. Geosci., 1, 221-227, 2008.

Ramanathan, V., Chung, C., Kim, D., Bettge, T., Buja, L., Kiehl, J. T., Washington, W. M., Fu, Q., Sikka, D. R., and Wild, M.: Atmospheric brown clouds: Impacts on South Asian climate and hydrological cycle, P. Natl. Acad. Sci., 102, 5326-5333, 2005.

Ramanathan, V., Crutzen, P. J., Kiehl, J. T., and Rosenfeld, D.: Aerosols, Climate and the Hydrological Cycle, Science, 294, 2119-2124, doi:10.1126/science.1064034, 2001.

Randles, C. A. and Ramaswamy, V.: Absorbing aerosols over Asia: A Geophysical Fluid Dynamics Laboratory general circulation model sensitivity study of model response to aerosol optical depth and aerosol absorption, J. Geophys. Res., 113, D21203, doi:10.1029/2008JD010140, 2008.
Tafuro, A. M., Kinne, S., De Tomasi, F., and Perrone, M. R.: Annual cycle of aerosol direct radiative effect over southeast Italy and sensitivity studies, J. Geophys. Res., 112(D20), D20202, doi:10.1029/2006JD008265, 2007.

Tindale, N. W. and Pease, P. P.: Aerosols over the Arabian Sea: Atmospheric transport pathways and concentrations of dust and sea salt, Deep-Sea Res. II, 46, 1577-1595, 1999.

Wang, C., Kim, D., Ekman, A. M. L., Barth, M. C., and Rasch, P. J.: Impact of anthropogenic aerosols on Indian summer monsoon, Geophys. Res. Lett., 36, L21704, doi:10.1029/2009GL040114, 2009.

Winker, D. M., Pelon, J., and McCormick, P.: The CALIPSO mission: Spaceborne lidar for observation of aerosols and clouds, Soc. Photo-Opt. Instru., 4893, 1-11, 2003.

Winker, D. M., Hostetler, C. A., Vaughan, M. A., and Omar, A. H.: CALIOP Algorithm Theoretical Basis Document, Part 1: CALIOP Instrument, and Algorithms Overview, NASA Langley Research Center, http://www-calipso.larc.nasa.gov/resources/ pdfs/PC-SCI-202.Part1_v2-Overview.pdf, last access: 17 February 2010, 2006.

Xia, X. and Zong, X.: Shortwave versus longwave direct radiative forcing by Taklimakan dust aerosols, Geophys. Res. Lett., 36, L07803, doi:10.1029/2009GL037237, 2009.

Xia, X., Wang, P., Wang, Y., Li, Z., Xin, J., Liu, J., and Chen, H.: Aerosol optical depth over the Tibetan Plateau and its relation to aerosols over the Taklimakan Desert, Geophys. Res. Lett., 35, L16804, doi:10.1029/2008GL034981, 2008. 